\title{
LINGUAGENS, VOZES E DISCURSOS: IDENTIDADES DE UMA TRABALHADORA DOMÉSTICA
}

\author{
(Language, Voice and Discourse: Identities of a domestic worker)
}

\author{
Franciene Soares Barbosa de Andrade ${ }^{1}$ \\ Universidade de Brasília \\ Mariney Pereira Conceição² \\ Universidade de Brasília
}

\begin{abstract}
RESUMO
O objetivo deste artigo é investigar marcas identitárias de uma trabalhadora doméstica buscando compreender os motivos que a levaram a assumir uma identidade de analfabeta. Os pressupostos teóricometodológicos são norteados pela ADC (FAIRCLOUGH, 1999,2016), a Pedagogia Crítica de Freire (1979, 1981) e Hall (2006) e Norton (2000) para discussões acerca de identidades. Uma entrevista semiestruturada e duas narrativas visuais (MELO-PFEIFER, 2015) são os instrumentos para a geração dos dados. A participante assume a identidade de analfabeta, nega suas origens - a roça -, assumindo o modo de falar da cidade como o correto e como um espaço digno de sobrevivência.
\end{abstract}

Palavras-chave: Linguagens. Discursos. Identidades.

\begin{abstract}
:
The aim of this article is to analyze the discourses of a domestic worker in order to understand the reasons that led her to assume an identity of an "illiterate". The theoretical-methodological assumptions are guided by the ADC (FAIRCLOUGH, 1999, 2016), Freire's Critical Pedagogy (1979, 1981) and Hall (2006) and Norton (2000) as bases for discussions about identities. A semi-structured interview and two visual narratives (MELOPFEIFER, 2015) are the instruments for generating the data. The participant assumes the identity of illiterate, denies her origins - the countryside -, assuming the way of speaking about the city as correct and as a space worthy of survival.
\end{abstract}

Keywords: Language. Discourse. Identities.

\section{RESUMEN}

El propósito de este artículo es investigar las marcas de identidad de una trabajadora doméstica que buscando entender las razones que la llevaron a asumir una identidad analfabeta. Los teóricos y metodológicos están guiados por el ADC (FAIRCLOUGH,1999, 2016), Pedagogía Crítica de Freire (1979, 1981) y Hall (2006) y Norton (2000) para discusiones sobre identidades. Una entrevista semiestructurada y dos narrativas visuales (MELO-PFEIFER, 2015) son los instrumentos para generar los datos. La participante asume la identidad de analfabeta, niega sus origens, el campo, asumiendo el manera de hablar de la ciudad como la correcta y como un espacio digno de supervivência.

Palabras clave: Linguaje. Discursos. Identidades.

\footnotetext{
${ }^{1}$ Franciene Soares Barbosa de Andrade é doutoranda do Programa de Pós-Graduação em Linguística (PPGL/UNB). Mestre em Processos de Desenvolvimento Humano e Saúde (PGPDS/ UnB). Especialista em Desenvolvimento Humano Educação e Inclusão Escolar (UnB) e Psicopedagogia. Licenciada em Pedagogia. Professora alfabetizadora da SEE-DF.

${ }^{2}$ Mariney Pereira Conceição é doutora em Linguística Aplicada pela Universidade Federal de Minas Gerais e pósdoutora pelo Laboratório da Linguagem e Processos Cognitivos da Universidade Federal de Santa Catarina. É Professora do Departamento de Línguas Estrangeiras e Tradução da Universidade de Brasília, atuando no Programa de Pós-Graduação em Linguística. Suas áreas de interesse envolvem processos identitários no ensino aprendizagem e formação de professores de línguas.
} 
Recebido em: julho 2020

Aceito em: julho 2020

DOI: $10.26512 /$ les.v21i1.32451

\section{INTRODUÇÃO}

Neste trabalho, temos como objetivo investigar marcas identitárias de uma trabalhadora doméstica buscando compreender os motivos que a levaram a assumir uma identidade de analfabeta ${ }^{3}$. Norton (2000) define identidade como a compreensão de uma pessoa a respeito da forma como sua relação com o mundo é estruturada ao longo do tempo e do espaço. A autora reafirma o papel da linguagem como construtora da identidade do/a aprendiz e, ao mesmo tempo, construída por ela, destacando a necessidade do desenvolvimento de uma teoria de identidades que integre o/a aprendiz com o seu contexto de aprendizagem (NORTON, ibid.), tendo em vista as relações de desigualdade a que estão submetidos os sujeitos. Segundo a autora, as características que podem 'definir' os sujeitos em relação à aprendizagem são socialmente construídas em contextos de relações desiguais de poder, "mudando segundo o tempo e o espaço e, possivelmente, coexistindo contraditoriamente em um mesmo sujeito" (NORTON, 2000, p. 5).

Dessa forma, falar de identidades provoca uma necessidade de falar também das condições oferecidas ao indivíduo para ser e para definir suas posições no mundo. Para Norton (2013), a noção de identidades envolve desejos de reconhecimento e afiliação, desejos estes que não podem ser separados da distribuição de recursos materiais na sociedade. As pessoas que têm acesso a uma ampla gama de recursos em uma sociedade terão acesso a poder e privilégios, que, por sua vez, influenciarão como elas entendem sua relação com o mundo e suas possibilidades para o futuro.

Os pressupostos teórico-metodológicos desta pesquisa qualitativa são norteados pela Análise de Discurso Crítica (ADC), pelos estudos de Fairclough (1999, 2016), pela Pedagogia Crítica de Freire $(1979,1981)$ e por Hall (2006) e Norton (2000), como base para as reflexões acerca de identidades. Nessa perspectiva, discutimos, inicialmente, a transdisciplinaridade entre a ADC e a Pedagogia Crítica como possibilidades de transformação social, problematizando que é fundamental reconhecer a dialética entre os discursos e as estruturas sociais. Neste artigo, discorremos a respeito do tema identidades no sentido de reconhecer que, ao falarmos sobre identidades, provocamos, também, uma necessidade de falarmos de condições para, por meio da emancipação e do agenciamento humano, contribuir para mudanças nas práticas sociais que possibilitam a construção e (re) construção de processos identitários.

\footnotetext{
${ }^{3}$ O termo é utilizado, aqui, com base em Soares (2010, p. 20), segundo a qual o analfabeto "é aquele que não pode exercer em toda a sua plenitude os seus direitos de cidadão, é aquele que a sociedade marginaliza, é aquele que não tem acesso aos bens culturais de sociedades letradas e, mais que isso, grafocêntricas".
} 


\section{A Análise de Discurso Crítica e a Pedagogia Crítica: Possibilidades de TRANSFORMAÇÃO SOCIAL}

A ADC ocupa um lugar de destaque nos estudos da linguagem na atualidade principalmente no que se refere às suas contribuições para outras áreas do conhecimento, sendo considerada um fio condutor teórico-metodológico na medida em que se propõe a dialogar com outras teorias (MAGALHÃES, 2005).

Para Brandão (2004), o entendimento da linguagem não mais centrado na língua como uma ideologia neutra dá hoje lugar ao discurso. Assim, a linguagem na qualidade de discurso se (re)significa e se desfaz da concepção de signo como ferramenta de comunicação ou apoio do pensamento. Quando se afirma, portanto, que não existem ideologias independentes da linguagem, infere-se que a construção de ideias realiza-se somente na gênese discursiva que pode ser revelada por diversas formas de expressão (RESENDE; RAMALHO, 2010).

Nesse sentido, a Pedagogia Crítica de Freire $(1981,2005)$ coaduna com a ADC ao defender uma prática social crítica para a libertação e não para servir a lógica do capital, que perpetua conhecimentos e valores condizentes com a legitimação dos seus interesses. Como propõem Hawkins e Norton (2009), a pedagogia crítica é engajada com a ação social e com a transformação educacional:

Enraizada no trabalho de Paulo Freire, educador brasileiro cuja missão era a emancipação dos camponeses na cultura colonial e nas sociedades pós-coloniais, a pedagogia crítica procura empoderar as pessoas para desafiarem as condições opressivas em suas vidas (HAWKINS; NORTON, 2009, p.31). ${ }^{4}$

Ao considerar a linguagem como uma prática social, a ADC proposta por Fairclough (2016) busca problematizar dialeticamente as relações entre discurso e prática social. O estudo da linguagem, segundo Fairclough (2016, p. 20), deve prescindir de uma "visão estática das relações de poder com ênfase exagerada no papel desempenhado pelo amoldamento ideológico dos textos linguísticos na reprodução das relações de poder existentes"

As mudanças discursivas podem provocar transformações sociais, assim como o social fomenta o discurso. A partir dessa relação dialética, a linguagem como discurso pode reverberar a partir da ação das pessoas sobre o mundo e sobre os outros. Com isso, "implica ser o discurso um modo de ação, uma forma em que as pessoas podem agir sobre o mundo e especialmente sobre os outros, como também um modo de representação" (FAIRCLOUGH, 2016, p. 94).

\footnotetext{
${ }^{4}$ Do original: "Rooted in the work of Paolo Freire, a Brazilian educator whose mission was the emancipation of peasants in colonial and postcolonial societies, critical pedagogy seeks to empower people to challenge oppressive conditions in their lives." (HAWKINS; NORTON, 2009, p. 31).
} 
Nessa perspectiva, ao mesmo tempo em que o sujeito é constituído sob a repressão de exigências dominantes, estas despertam uma ação para a transformação, fazendo emergir um sujeito agente nesse processo, à medida em que experimenta e cria novas possibilidades de significar a linguagem, alcançando novos modos de revalidar saberes já descobertos, antes ocultados pelas relações de poder nos contextos sociais (FAIRCLOUGH, 2016).

É importante, assim, como destaca Freire (1979, 2002), reconhecer o sujeito a partir da sua substancialidade, uma vez que o que é dado ao ser humano não pode se sobrepor a um dos fatores mais importantes de sua existência, que é o seu estar no mundo como sujeito histórico e cultural. Partindo desse ponto de vista, é preciso reconhecer a dualidade do ato discursivo, que pode seguir tanto por caminhos padronizados, como trilhar percursos ousados, dinâmicos e criativos, contribuindo para transformar a sociedade (FAIRCLOUGH, 2016). Uma prática social alicerçada apenas em ideologias formalistas não permite a vivência dessas práticas críticas e libertadoras, pois instrumentaliza o sujeito para atuar dentro de um contexto puramente serviente, consumista, individualista e capitalista (FREIRE, 2002).

Uma compreensão dialética sobre a dualidade do ato discursivo se faz pertinente, nas palavras de Freire (1981), ao enfatizar que é preciso acreditar em uma pedagogia da indignação. Assim, é imprescindível a busca por uma pedagogia crítica da construção diante das afirmações da vida. Segundo o autor, a educação como prática da liberdade não admite o ser abstrato, isolado e desconectado do mundo. Ao contrário, os sujeitos devem ser vistos sob um viés dialógico e, de tal modo, alcançar transformações sociais e (re)construções identitárias.

\section{LINGUAGENS E IDENTIDADES: UMA LÍNGUA PADRÃO?}

Segundo Hall (2006), “as velhas identidades, que, por tanto tempo, estabilizaram o mundo social, estão em declínio, fazendo surgir novas identidades e fragmentando o indivíduo moderno, até aqui visto como um sujeito unificado" (p.7). Diferentes identidades influenciadas pela história, política, representação e diferenças configuram o novo sujeito pós-moderno (HALL, ibid.).

A pós-modernidade tem sido marcada pela globalização, que, com o advento das tecnologias, supera a distância nas interações, modificando as relações espaço/tempo. Conforme destacam Chouliaraki e Fairclough (1999), essa era da globalização, caracterizada por uma nova organização social, carece de uma consciência crítica da linguagem como parte dos recursos dos sujeitos sociais para conviverem de novos modos e em novas posições. Faz-se necessário, assim, criar condições, por meio de uma consciência crítica da linguagem, para que os sujeitos analisem seu estar no mundo diante da dialética entre o global e o local. 
Hawkins e Norton (2009) destacam que o ensino de línguas para migrantes deve evitar o caráter opressor, possibilitando aos sujeitos a inserção na sociedade. Neste artigo, propomos, da mesma forma, uma discussão a respeito da necessidade dessa reflexão nos contextos de migrações regionais no Brasil, por pessoas em busca de melhores condições de vida. Contrariando a ideia de que migrantes devem absorver significados tidos como naturalizados e verdadeiros em determinada cultura, advogamos, portanto, uma intervenção crítica diante desses discursos, uma vez que, se as identidades são vistas como múltiplas, a própria multiplicidade das identidades pode ser aproveitada de maneira produtiva, a fim de que se possa ampliar as possibilidades humanas e inserir indivíduos marginalizados na sociedade (NORTON, 2016).

A linguagem não se restringe à estrutura linguística de palavras e sentenças, mas se constrói por meio da identidade de quem fala, ou seja, é considerada também uma prática social na qual identidades são contextualmente negociadas nas complexas interações sociais, em sua maioria, desiguais (NORTON, 2013). Ainda nesse sentido, as identidades articulam-se não apenas com a vida coletiva de uma sociedade, nas interações sociais que as constituem, mas também com os processos de constituição simbólica ou representações sociais, nos quais sujeitos sociais buscam dar sentido ao mundo e nele encontrar o seu lugar, através de uma identidade social (MOSCOVICI, 2013). Essa dinâmica entre a linguagem e a existência prática da vida é vista em Freire (1989) como uma leitura de mundo que antecede a decodificação da palavra. Essa leitura de mundo, como sugere Freire (ibid.) permite enxergar cada sujeito como participante no mundo, com o mundo e com o outro.

Diante dessas considerações sobre a linguagem como discurso que reorganiza experiências e produz identidades, é preciso salientar a importância da (re)significação dos processos de norma culta e variação linguística. Para Bakhtin (2006), seria um grande equívoco afirmar que a língua é essencialmente objetiva na sua normatividade estabilizada e incontroversa. A língua não se faz em consonância com a norma culta ao ser utilizada, mas na (re)significação que essa estrutura linguística assume ao ser contextualizada. O código imutável equivale a si mesmo, mas torna-se significativo na forma variável e flexiva, e, com isso, identifica-se uma característica inovadora não exclusivamente de ajustamento à norma. É nesse sentido que a língua passa a ter importância linguística, pois “a pura 'sinalidade' não existe, mesmo nas primeiras fases da aquisição da linguagem. Até mesmo ali, a forma é orientada pelo contexto, já constituindo um signo" (BAKHTIN, 2006, p. 95).

Shor e Freire (1986) também apresentam uma discussão acerca das desordens políticas entre a língua padrão e a língua coloquial. Os autores destacam o quanto a linguagem do dia a dia é diferente da linguagem denominada culta e da gramática válida tradicional. Para os autores, faz-se necessário construir uma linguagem que elimine esse distanciamento, já que essas questões de linguagem não 
são problemas estritamente "linguísticos ou pedagógicos", ou seja, "a classe dominante tem o poder de estabelecer a sua linguagem como padrão" (SHOR; FREIRE, 1986, p.178).

É importante destacar, que, neste estudo, nos reportamos às abordagens críticas já mencionadas aqui, no sentido de buscar uma reflexão acerca de como o sujeito sócio-histórico ora constituí, ora é constituído pelo meio em que se encontra situado. É preciso promover ações que possam diminuir os distanciamentos entre classes e as injustiças sociais, em especial, no momento atual, em que migrações motivadas por buscas por melhores condições de vida tornam-se cada vez mais crescentes, não apenas em contextos internacionais, mas também em contextos internos, dadas as diferentes condições de qualidade de vida em diferentes regiões, como é o caso no Brasil.

\section{Metodologia}

Esta pesquisa se fundamenta nos pressupostos metodológicos da ADC, como proposta por Fairclough (2016), associada a uma pesquisa de cunho qualitativo. A ADC, como metodologia de pesquisa, faz-se pertinente neste estudo por tratar das práticas discursivas associadas ao âmbito social, buscando reconhecer os traços históricos que as práticas culturais e sociais podem evidenciar. Ademais, permite somar diversas perspectivas críticas na investigação de um problema social que se constrói nas relações sociais de poder, e, frequentemente, é velada no discurso. Nessa perspectiva, o discurso não é mera prática social, "mas é considerado como elemento semiótico das práticas sociais, incluindo não só a linguagem, como também a comunicação "para-verbal” (expressões faciais, movimentos do corpo, os gestos), bem como as imagens visuais" (DIAS, 2011, p. 215).

A abordagem qualitativa foi também utilizada na pesquisa, buscando-se uma aproximação maior do pesquisador com a realidade estudada, já que este tipo de pesquisa caracteriza-se por uma preocupação com o comportamento humano, a partir da referência do próprio indivíduo (BOGDAN; BIKLEN, 1994). Como destacam esses autores, a abordagem qualitativa auxilia o pesquisador ou pesquisadora a compreender os dados no contexto histórico e social em que se encontram situados (p.19). Neste estudo, ${ }^{5}$ ao salientarmos a importância das narrativas de experiências para a reorganização de novos discursos e práticas, buscamos elucidar a relevância da linguagem a partir do social. Nos parágrafos que se seguem, apresentamos o contexto de realização do estudo e a participante, assim como os procedimentos para a geração e análise dos dados.

Iniciamos este estudo traçando seu desenho de forma que pudéssemos não apenas investigar processos de construção de identidades envolvendo uma realidade específica, a de uma trabalhadora

\footnotetext{
${ }^{5}$ É importante ressaltar que o estudo foi realizado conforme as normas éticas para trabalhos científicos na Universidade de Brasília e submetido à Plataforma Brasil, base nacional e unificada de registros de pesquisas envolvendo seres humanos.
} 
doméstica em condição de analfabetismo, mas, que, por meio da pesquisa, pudéssemos prover condições para a emancipação e fortalecimento das identidades da participante ${ }^{6}$, oferecendo a ela uma oportunidade de alfabetização ${ }^{7}$. Jéssica, no entanto, recusou a oferta e passamos, então a oferecer a ela outras possibilidades, como a matrícula em cursos ou escolas, conforme preferisse. Em todas as instâncias, Jéssica reafirmou, fortemente, sua posição de não desejar aprender a ler e escrever, destacando que já havia tido várias oportunidades para tal e recusado todas elas. Decidimos, então, dar prosseguimento ao estudo, investigando a construção de identidades de Jéssica, visando compreender os motivos que a levaram a assumir a identidade de analfabeta.

Jéssica, a participante do estudo, tem 43 anos de idade, nasceu na região nordeste do Brasil (Rio Grande do Norte) e é trabalhadora doméstica em Brasília, Distrito Federal, na residência de uma das autoras deste trabalho. Jéssica é a oitava filha de uma família constituída por dez irmãos, além do pai e a mãe. Entre os irmãos, cinco são homens, cinco são mulheres. Jéssica passou sua infância morando e trabalhando na zona rural do estado de Rio Grande do Norte. Ao completar 18 anos, mudou-se para Brasília em busca de emprego e melhores condições de vida. Após ter passado por um processo de separação conflituoso do seu esposo, deixou seus dois filhos no Rio Grande do Norte um aos cuidados de sua mãe e outro na guarda do pai da criança. Quando Jéssica chegou a Brasília, entrou em um processo melancólico, decorrente da separação abrupta dos filhos, mas foi amparada por suas amizades e por seus empregadores, como declarou. A escolha da participante da pesquisa não foi determinada por um critério específico, a não ser a participação voluntária. O consentimento para a participação no estudo deu-se, não apenas por meio de acordo oral entre as partes, mas também por meio de assinatura de termo de consentimento livre e esclarecido, já que Jéssica, embora não pudesse ler e escrever, sabia assinar seu nome. Assim, após conversa e elucidação da pesquisa, o termo de consentimento foi lido para a participante e ela o assinou.

Quanto aos procedimentos para a coleta e geração dos dados, duas narrativas visuais (MELO-PFEIFER, 2015) foram utilizadas como forma de acessar exemplos de vivências e histórias de vida da participante, que não sabia ler e escrever, permitindo que ela reproduzisse suas experiências por meio de um desenho. Como destaca Melo-Pfeifer (2015), imagens visuais são, cada vez mais, uma característica muito importante da vida contemporânea. Por meio da utilização de narrativas visuais para a coleta e geração de dados, conforme a autora propõe, o pesquisador ou pesquisadora é capaz de ampliar o seu olhar para aspectos como cores empregadas no desenho, uso

\footnotetext{
${ }^{6}$ A participante do estudo será identificada neste trabalho por Jéssica, pseudônimo escolhido por ela.

${ }^{7}$ A proposta de alfabetização em questão teria como base as perspectivas sociolinguísticas e funcionais da linguagem, considerando o caráter arbitrário de todo código linguístico e a coexistência de diferentes variedades de uso (BAGNO; STUBBS; GAGNÉ, 2002, p. 206).
} 
de elementos e objetos, assim como a presença de diversas linguagens. A autora ressalta, ainda, que narrativas visuais abrem possibilidades para que se possa captar experiências e sentimentos sobre as vivências contextualmente marcadas por diferentes culturas. Foi pedido, assim, à participante, que se desenhasse, representando a forma como se percebia. A participante utilizou duas folhas, apresentando duas narrativas visuais diferentes, as quais, segundo ela, representavam o lugar em que nasceu e viveu sua infância (Narrativa Visual 1 - ver Figura 1), e como ela se via atualmente, no momento em que a coleta foi realizada (Narrativa Visual 2 - ver Figura 2). Na sequência da coleta de dados, uma entrevista semiestruturada foi utilizada como principal instrumento na coleta e geração de dados neste trabalho, por permitir elucidar a subjetividade da participante, tendo em vista a não obrigatoriedade de se seguir um roteiro rígido, mas que permitisse à participante pensar e refletir sobre suas experiências e percepções e enunciar sua divergência ou concordância em relação às perguntas e/ou declarações feitas (FLICK, 2010).

A análise dos dados foi realizada com base nos pressupostos teórico-metodológicos da ADC, tendo sido adotados os seguintes passos para os procedimentos de análise na pesquisa qualitativa: i) leitura cuidadosa de todas as respostas à entrevista transcritas, a fim de buscar unidades significativas e agrupá-las em temas semelhantes para elaboração das categorias de análise; ii) análise das narrativas visuais também identificando as unidades significativas por meio da leitura e interpretação, pelas pesquisadoras, dos desenhos realizados pela participante, assim como suas declarações com respeito aos desenhos durante a entrevista e iii) leituras recorrentes dos dados que emergiram na análise. A análise de textos, como parte da análise de discursos, possibilita informações para o entendimento das práticas sociais. A partir dos "textos (produzidos em eventos discursivos situados) podemos compreender o funcionamento social dessas práticas” (RESENDE; RAMALHO, 2011, p. 22).

\section{ANÁLISE E DISCUSSÃo DOS DADOS}

\subsection{Infância e Escola: Circunstâncias de não aprender a ler e escrever}

Ao iniciarmos a entrevista a partir de um tópico amplo, solicitando à participante que falasse um pouco a respeito de suas experiências na infância, a expressão inicial da participante [1] "Vixi Maria! Misericórdia", 8 seguida de risos desconcertantes, marca, em sua fala, um momento que parece ter sido difícil. Voltar ao tempo de criança fez emergir, naquele momento, uma identidade fragilizada, que parecia não ter voz, mas, logo, em tom de voz firme, a participante responde: [2] "Eu vou falar".

\footnotetext{
8 As falas da participante não foram editadas.
} 
A entonação de Jéssica era de indignação, que parecia ressoar como um "agora eu posso falar, agora ninguém me impede de falar":

[3] Eu trabalhei muito de roça... não tivemo oportunidade di estudá..

intendeu?... A gente não saía muito a gente não teve infância éééé né... (...)o negócio dos nossos pai só era trabalhar de roça... é que mais... fazer as atividade de casa éééé que mais...a gente não saia pra lugar nenhum (...) e ainda apanhando mais ainda (risos) entendeu? (Jéssica, Entrevista)

Apesar de a pergunta se dirigir à participante, ela utiliza a expressão "a gente", buscando envolver os membros de sua família, seus irmãos que compartilharam essas experiências com ela. Jéssica destaca, de forma enfática, que ela e os irmãos não tiveram infância porque não frequentaram a escola quando pequenos e não tiveram liberdade para sair para outros lugares, pois tinham de trabalhar na roça e realizar os afazeres de casa. Ainda que seu pai tenha imposto um modelo de infância voltada para a classe social e realidade socioeconômica da família e, até mesmo de costumes enraizados, comportamentos condicionados e rotinas estabelecidas historicamente comuns na realidade da área rural brasileira, Jéssica, como um sujeito social no momento histórico da entrevista, encontra uma oportunidade para se ver de outra maneira, e se revolta por ter tido a sua infância "roubada", segundo ela mesma afirma. Assim, compreendemos que o conceito concretizado de infância para Jéssica era de ter liberdade para sair (e de frequentar a escola). Revela-se, aqui, o desejo de explorar outros ambientes diferentes da roça e de sua moradia. Ela destaca:

[4]... a minha infância foi depois que eu cheguei aqui em Brasília, acredita... que eu tive infância depois de 18 anos que foi minha infância porque quando a gente tava lá a gente vivia presa, né só dentro de casa sem saí pra canto nium aí quando eu cheguei aqui pronto ai não tinha ninguém pra me prendê mais aí eu danei a andá aí foi que eu tive infância (Jéssica, Entrevista).

O excerto nos remete às palavras de Hall (2006), segundo o qual as velhas identidades, que, por tanto tempo pareciam estabilizar o mundo social, estão agora em declínio, fazendo surgir novas identidades e fragmentando o indivíduo, antes visto como um sujeito unificado, inserido em sua classe, gênero, sexualidade, etnia, raça e nacionalidade. As identidades, como as percebemos aqui, não são mais circunscritas em um ser ou espaço temporal coerente, mas são dinâmicas que se constroem e reconstroem constantemente, nos processos sócio-históricos e culturais (HALL, 2006).

A participante alega que apenas aos doze anos de idade foi para a escola e, como não foi desde pequena, perdeu completamente a vontade de estudar. Para a participante, a escola tornou-se palco de brincadeiras, talvez em função de uma infância reprimida, pois, em vez de brincar, tinha que realizar tarefas de adulto e trabalhar. A simbolização da escola volta-se, assim, mais para a questão da liberdade reprimida, algo bastante reivindicado pela participante, do que para aprender. Nesse momento da entrevista, podemos observar um discurso de resistência a aprender a ler e a escrever por 
parte de Jéssica. A participante alega que, se não aprendeu quando pequena, porque os pais não o permitiram, não desejava e não poderia mais aprender:

[5]..tinha.. hum hum.. tinha escola bem pertinho de casa...(...) eles queria que a gente trabalhasse muito de roça.. (...) não colocou a gente na escola quando a gente era mais pequeno....(..). a gente já grande com doze treze ano aí nem qué mais saber de estudá. que saber de tá namorando de i atrás de festa, intendeu? Então a gente nem ligou pra escola.. não deu mais nem.. não teve mais nem vontade de estudá. não teve mais interesse... Nós não ia pra estuda, nós ia pra brincá.. (...) a gente num aprendeu mais por causa disso... porque a gente já foi grande pra escola (Jéssica, Entrevista).

Quando perguntada sobre a frequência da vizinhança na escola, Jéssica afirmou que via muitas crianças indo para a escola enquanto ela e seus irmãos iam para a roça. Seu tom de voz entristecido demonstra ter sido difícil não ter frequentado a escola na infância, como as outras crianças. A participante acrescenta, ainda, que ela e seus irmãos não haviam estudado porque seus pais tinham preocupação somente com o alimento. Observa-se, aqui, a legitimação da crença, contextualizada histórica e culturalmente, de que se a criança está alimentada já é o suficiente e o necessário.

[6]... tinha muito vizinho morando lá perto da gente.. a gente via o pessoal.... as crianças ino lá pra escola... (...) eles passava bem pertinho lá de casa aí a gente tava indo pra roça aí via eles ino pra escola aí a gente ficava (voz triste) com vontade de ir pra escola mas não tinha como i pra escola... os dois num deixava...o pessoal de antigamente que só lembrava da barriga de... colocar o sustento dento di casa né? (Jéssica, Entrevista)

Jéssica relata-nos, ainda, que seu contato com a leitura e a escrita se deu através das primas que moravam perto de sua casa e liam para ela. Em um tom enfático, Jéssica ainda destaca que suas primas estudaram muito e, hoje, são quase todas formadas. Jéssica declara ter tido vontade de ler, mas sempre remete à afirmação de que os pais não a deixaram estudar. Ao refletir sobre as primas, ela ressalta o fato de que, apesar de ter frequentado pouco a escola, pelo menos aprendeu a escrever o nome, não tão bem, mas aprendeu, colocando uma irmã em uma posição pior, porque nem isso aprendeu:

[7] (...) Elas estudou e muito (enfática) elas são quase tudo formada hoje em dia... intendeu? (...) elas lia pra gente...(...) só que eu... os pai da gente não deixava a gente $i$ né?(...) Aquela minha irmã (...) sabe nem assiná o nome... pior do que eu... que nem o nome aprendeu.. eu ainda fui, né? Na adolescência eu fui pa escola eu ainda aprendi o nome... escrito que nem minhas venta...mas ainda aprendi...e ela que num sabe é de nada... eu acho que ela num sabe nem a data di nascimento dela... e o ano que ela nasceu. Acho que ela nem sabe.. intendeu? (Jéssica, Entrevista).

Em relação a preconceitos pelo fato de ter ido já adolescente para a escola sem saber ler e escrever, Jéssica diz, em tom de voz triste e apático, não ter sofrido nenhum preconceito na escola porque todos em sua sala de aula, segundo ela afirma, tinham a mesma realidade. Ela repete, em tom 
de voz melancólico, o quanto não se interessava pela escola. Surge então um fato que precisa ser comentado: Jéssica declara, como um assunto velado pelo tom de voz mais baixo, que os irmãos sofreram, pois na turma dos irmãos era diferente, havia alguns alunos que já sabiam ler e escrever. Ela afirma que, por causa do preconceito, seus irmãos até apanhavam dos colegas na escola. Ela ressalta que, além da irmã mais nova, estes foram os dois únicos irmãos que aprenderam a ler. Inferese, assim, que os dois irmãos que aprenderam a ler possivelmente frequentaram mais a escola, pelo fato de serem homens, e a irmã mais nova pelo fato de já ter vivido em outro momento históricocultural. Observa-se, portanto, que a questão de gênero, tempo e espaço pode ter influenciado na questão de não aprender a ler e escrever e nessa manutenção da resistência de não querer retomar a possibilidade de aprender. O seu tom de voz, somado à contextualização que ela mesma traz e à forma como relata a situação criada pelo fato de ela ser mulher, leva a crer que os preconceitos aconteceram, mas não foram vistos por ela como preconceitos. Jéssica destaca, mais uma vez:

[8] Não (tom de voz triste), a gente nem dava ideia pra escola, sabe? (...) não prestava atenção pro que a professora tava falando... era só conversano (...)Não (voz firme)... não porque tipo assim os que tava lá era tudo junto com a gente... não tinha estudo... era igual a gente sem estudo... entendeu? Tava lá para aprender igual nós.. mas meus irmão passou por essas coisas... por preconceito (abaixou o tom de voz) porque não sabia (abaixou mais o tom de voz) porque eles não sabia ler nem escrever e tinha uns lá que já sabia junto com eles, né? Até apanhava eles .. meus dois irmão mais véi... que foi eles dois que sabe ler.. só eles dois e aquela minha irmã (...)....eles passaram .. os menino ficavam brigano com eles. bateno neles.. intendeu? judiaram muito deles na escola, deles dois.. foi só.. mas a gente não porque a gente era tudo igual, né (Jéssica, Entrevista).

No ambiente escolar, a obrigação de ter interesse pelos estudos parecia recair somente sobre Jéssica, independente da condição ou do contexto em que ingressou na escola:

[9] ...eu não tenho mais interesse.. eu não tenho mais fé que eu possa aprender.. eu acho que a idade da gente aprender é quando (...) você é uma criança você não tá com seu pensamento em nada.. entendeu é só ali lá na escola.. (...) depois de adulto se não tem interesse por nada seu interesse é só pra você ficá, andá i pra loja comprá as coisa.. igual a gente tava lá e ia pa escola a gente não tinha interesse não a professora falava o interesse é de vocês eu tô só pa ensina e o interesse é de vocês... (Jéssica, Entrevista).

Freire (1989) ressalta o quanto é pertinente compreendermos que é de interesse do poder ideológico dominante que recaia sobre os dominados a responsabilidade por sua condição. Nesse sentido, Bakhtin (2006) também nos lembra que "as palavras estão sempre carregadas de um conteúdo ou de um sentido ideológico ou vivencial" (p.96). É preciso reconhecer, assim, que as circunstâncias de não aprender a ler e escrever não se resumem a questões individuais, mas perpassam por vários aspectos. A legitimação da crença discriminatória de que o fato de Jéssica ser do Nordeste e morar na roça, por si só, já bastaria para justificar o seu analfabetismo, não se afirma nesta pesquisa. Ao contrário, entendemos que a resistência de Jéssica em aprender a ler e escrever é perpassada pela 
sobreposição e interdependência de outros fatores contextuais, como a classe social a que pertence, assim como às questões relacionadas ao gênero, espaço e tempo que influenciaram o seu não aprender a ler e escrever na infância. Como destaca Norton (2016), é preciso considerar a intersecção de categorias sociais na análise dos dados quando voltamos o nosso olhar para participantes em condições menos favorecidas como é o caso da participante do estudo.

Nessa intersecção de fatores que influenciaram a decisão de Jéssica em assumir uma identidade de não escolarizada, muitas questões parecem entrelaçadas, entre estas, as representações de Jéssica em relação à sua própria capacidade de aprender ou não, nessa fase da vida, quando já adulta. Em sua entrevista, ela destaca:

[10]...mas como eu não tive essa oportunidade de aprender ler escrever eu... vou ficar assim... não tem mais jeito... não tem mais solução, ficá assim mesmo... porque não quero mais...intendeu? (Jéssica, Entrevista).

[11]...aí eu já coloquei na minha cabeça que eu não aprendo a ler e escrever. Não quero aprender mais não (Jéssica, Entrevista).

Sendo as representações sociais uma teia de conceitos e imagens inter-relacionados (MOSCOVICI, 2013), é importante discuti-las aqui. Para tentar compreender uma representação em sua totalidade, é preciso que se observe cada detalhe da fala, da comunicação e das práticas sociais em que a representação está situada. Até que ponto, então, a recusa de Jéssica em aprender a ler e escrever constitui, de fato, uma recusa de sua parte e não apenas o resultado da representação de que não é mais capaz de aprender? Assim, a pergunta "Quem sou eu?", mais uma vez, não pode ser entendida à parte da pergunta "O que eu posso fazer?". Da mesma forma, a pergunta "O que eu posso fazer?" não pode ser compreendida à parte das condições materiais que estruturam oportunidades para a realização de desejos. $\mathrm{O}$ acesso de uma pessoa a recursos materiais pode definir os termos nos quais os seus desejos são articulados. Nessa visão, uma pessoa pode assumir diferentes identidades, com base em relações sociais (NORTON, 2013), assim como com base em suas representações (MOSCOVICI, 2013).

\subsection{Chegada à cidade: dificuldades, preconceitos e resistências}

Sobre a chegada de Jéssica na cidade em busca de emprego e por outros fatores pessoais já mencionados aqui, ela afirma que, inicialmente, sentiu-se mal, perdida, pelo fato de não saber ler e escrever, principalmente, na hora de pegar ônibus, mas depois foi se acostumando e aprendendo a se virar sozinha, não precisando perguntar mais a ninguém sobre seu ônibus. Porém, segundo a participante afirma, ela tomou o ônibus errado durante muito tempo e se sentiu como uma cega por 
não saber o que estava nas placas, mas, com o tempo, foi, nas palavras de Freire (1989), fazendo uma leitura de mundo:

[12] Eu me senti ruim... no começo quando eu cheguei aqui em Brasília... eu me senti...assim..perdida porque não sabia ler.. primeiro não sabia escrever .. não sabia ler.. intendeu? Aí pra pegar o ônibus era uma dificuldade.. tinha que tá perguntano o povo que foi bem no começo...aí eu passei aperto, mas depois eu fui me acostumano com aquilo aí fui pegar o ônibus sozinha sem tá perguntano mas pa ninguém porque não é todo mundo que ensina direito (voz firme) ainda peguei o ônibus várias vezes errado.. ficava perdida sem saber, né? porque tem uma placa ali se não sabe nem o que tá escrito lá.. igual mesmo que igual um cego.. você nem dá conta de lê... aí então foi assim eu me senti perdida... sem saber de nada (risos)... aí então eu aprendi foi passando o tempo eu fui me acostumano eu fui aprendendo prestano atenção onde que eu tava qual era o ônibus, intendeu? Aí eu fui aprendeno (Jéssica, Entrevista).

A dinâmica entre a linguagem e a existência prática da vida é vista em Freire (1989) com uma leitura de mundo que antecede a decodificação da palavra. A leitura de mundo permite enxergar cada sujeito como participante no mundo, com o mundo e com o outro. A partir dessa leitura de mundo, Jéssica explica, com satisfação e felicidade, que sabia ler "Setor O e P Norte", ao mesmo tempo em que, segundo ela, só sabia pegar esses dois ônibus, pois, quando tinha de ir para outro lugar, o marido a ensinava:

[13] (...) é o ônibus que tá escrito Setor O aí eu já sei que é Setor O.. intendeu? Setor O eu dou conta de lê (expressão feliz) aí o outro que eu pego é P Norte. Aí lá tá escrito P Norte é o 331 aí eu sei... eu também só do conta de pegar esse dois ônibus ôtos... (...) Aonde eu tiver que eu vê eu sei que é.. sei que é Setor O...sei que é P Norte, intendeu? Agora assim... pra i pra ôtos lugar assim... (...) quando precisa aí eu vô mais Lorival e Lorival me ensina, intendeu? Aí quando eu venho de lá pra cá aí eu já sei, intendeu? Quando eu fui aí eu já aprendi, intendeu, tem que aprender... é assim que a gente aprende as coisa, né?" (Jéssica, Entrevista).

Sobre preconceitos e discriminações sofridos ao chegar à cidade, ao ser indagada se havia sofrido algum preconceito no ambiente de trabalho, Jéssica responde em tom de voz baixo, afirmando que nunca havia sofrido esse tipo de preconceito. Ao ser novamente indagada se havia sofrido algum preconceito no ambiente de trabalho, a participante é enfática ao dizer que ninguém nunca falou nada e nem a mandou estudar e que agora nem se sente mal como se sentia no começo, alegando que não vai aprender mais porque, segunda ela, "tem a cabeça dura" e, por isso, (ela repete várias vezes em vários momentos da entrevista), não quer mais aprender. Se antes ela havia dito que nunca ninguém havia falado nada para ela ou dito a ela para estudar, agora conclui esse tópico da entrevista destacando que o atual marido sempre a aconselha a voltar aos estudos e que tem gente que a chama de "analfabeta". Ao ser indagada a respeito dos estudos do marido, ela reconhece o desinteresse do marido por não querer cursar a faculdade e afirma que ele tinha de cursar uma faculdade porque a irmã dele é funcionária pública. No entanto, Jéssica não reconhece que ela também pode avançar nos 
estudos. A participante, assim, inicialmente, nega um preconceito que aparece, posteriormente, em sua fala. Ela parece não ver como preconceito o fato de ser chamada de "analfabeta" e ser tomada como alguém que "não sabe ler e nem escrever". Essas palavras parecem já tão naturalizadas em sua existência que Jéssica não as percebe mais como preconceito, manifestando, novamente, resistência atual em relação a aprender a ler e a escrever:

[14]Não. Nunca... acredita (voz baixa) nunca.. nunca.. (...): não (voz fina) ninguém nunca falou nada, sabe? Assim vai estuda mulher (voz alta).. não.. você tá nova você ainda pode estudá..você pode sê alguém na vida.. ninguém nunca chegou e falou nada assim não. (...) As vezes eu fico comentano com o Lorival assim ah eu não vou aprendê mais mesmo.. eu tenho a cabeça muito dura.. eu não quero sabê disso mais não... porque ele fica falano Jéssica vai pra escola.. (...) aí eu digo ah não Lorival não quero não que eu não tenho mais (voz triste) (...) ele sabe lê ele terminô os estudo dele tudinho.. ele não fez uma faculdade porque ele não quis.. por que na época o pai dele queria pagá pra ele... Ele tem uma irmã que é funcionária pública também.. sabe? (...) e ele não quis nada aí tá aí oh sem trabalho.. (...) Porque porque ele quis.. porque ele não deu valor.. porque na (...) ele faz é me ajudá intendeu? As vezes tem umas menina ééé que manda éée no Whatsapp.. manda mensagem, sabe?.. não manda no áudio.. manda mensagem aí eu mando ele lê e ele lê tudo direitinho ele não fala nada ele nunca falou nada assim você... que tem gente que fala.. né? Aí você é analfabeta.. você não sabe lê você não sabe escrevê.. (tom de voz bravo, gritando) não ele nunca falô nada não.. nunca..ele só fala assim vai pa escola.. entendeu? Ainda tá em tempo de você aprendê.. ele fala desse jeito...eu não... (voz triste e baixa). (Jéssica, Entrevista).

Ao dialogar sobre onde ficaria à vontade para aprender a ler e escrever, Jéssica deixa registrado, de forma enfática, por várias vezes, não ter vontade de aprender a ler e escrever:

[15] Eu não tenho vontade... Eu vejo oh o pessoal ino pa escola.. que tem um monte de menina que mora lá perto de casa que vai pa escola.. quando eu chego lá eles tão ino pa escola. não me dá nenhuma vontade. eu tinha vontade quando eu era mais nova e aquele povo lá não deixô a gente i pa escola, intendeu? Então eu não tenho vontade pra mim passa por mim e eu nem ligo, sabe? Nem.. tem não.. se eu disse que tem eu tô mintino.. então não adianta minti.. eu não tenho vontade de i pa escola .. de aprendê. de escrevê.. eu não tenho.. de jeito nenhum... tenho não porque na minha vida eu não aprendi.. não tive oportunidade de i pa escola.. então eu não tenho vontade.. não penso em i.. eu não.. eu fico.. quando eu chego em casa. Eu fico quieta.. eu tomo meu banho.. aí vou fazê janta.. aí vou me deitá.. não eu não tenho vontade de i pa escola. de jeito nenhum (Jéssica, Entrevista).

O excerto nos revela a forma como Jéssica se percebe e como percebe suas possiblidades futuras quanto a aprender a ler e escrever. Como destaca Norton (2013), identidade é a "a maneira como a pessoa entende sua relação com o mundo, como essa relação é estruturada no tempo e no espaço e como a pessoa entende as possibilidades para o futuro" (p.4). Jéssica não percebe, no entanto, possibilidades futuras. Como destaca Fairclough (1999), para que as pessoas possam viver neste mundo complexo, em vez de apenas serem levadas adiante, elas precisam de recursos para examinar sua posição na sociedade e esses recursos incluem, como se observa aqui, a necessidade de uma consciência crítica de linguagem, assim como propostas de ações para que se possa criar 
possibilidades de mudanças futuras para pessoas em condições sociais menos favorecidas, como é o caso de Jéssica.

\subsection{Construindo e (re)significando identidades}

Ao nos depararmos com a aparência melancólica de Jéssica refletindo sobre sua condição durante a entrevista, tentamos falar de algo que lhe provocasse ânimo e lhe dizer que, mesmo ela não tendo aprendido a escrever e a ler, ela se expressava muito bem. A participante então disse timidamente, em tom de voz baixo, que muitas pessoas já haviam dito isso a ela. Ao falarmos sobre essa habilidade, ela, por um momento, quase expressou a palavra "inteligência", mas parou no meio da palavra, pois acreditava não ter permissão para reconhecer isso. Completou dizendo que o marido diz que ela é inteligente e que ela deveria ir para a escola. Em justificativa para não ir à escola, ela traz o exemplo da única irmã que aprendeu a ler e escrever e, no entanto, não sabe o quanto ela sabe e, mais uma vez, discorre sobre a sua vivência de mundo, sempre buscando justificar que não precisa aprender a ler e escrever porque ela sabe de coisas que quem sabe ler e escrever não sabe:

[16] Eu falo (voz baixa) (...) hum hum eu já ouvi isso de várias pessoas (...) acho que é intel.. não sei não (...) esses dias eu também tava falano pro Lorival..aí o Lorival disse assim.. Jéssica tu não sabe escrever tu não sabe ler e tu é tão inteligente porque você não vai pa escola mulher? Vai pa escola que você vai ser.. uma mulher tão inteligente.. ele falano, sabe? Aí eu digo eu não Lorival.. aí eu falei pra ele assim eu não sei Lorival porque eu não sou igual a Ana, intendeu? A Clara mesmo (voz de espanto) ela sabe ler sabe escrevê e a menina num sabe nem arrumá.. achá um indereço.. tudo perguntano pra mim..sabe? eu digo.. mulhé tu vai tem a praca tá expricando tudo direitinho..mas eu não sei Jéssica e eu vou sozinha sem indereço sem nada e eu consigo.. eu trabalhei lá na Asa Norte e lá na Asa Sul naqueles condomínio lá.. sabe? Aí na época que era pa i que eles ficava transferino de condomínio. Aí eles não me dava endereço não ele só falava e eu ia chegava lá e acertava, entendeu? (...) mas é bom a pessoa que lê que sabe lê sabe escrevê.. é bom.. mas pió que tem gente que igual eu tô lá na parada sabe.. eu vejo lá na parada.. tem gente que sabe lê sabe escrevê e pega aquele ônibus todo dia.. eu já vi isso muita vez... entra dento do ônibus e pergunta a mesma coisa pro motorista, motorista esse ônibus vai pro Setor O.. motorista esse ônibus vai pro P Norte.. aí o motorista tá ali.. A mulher tá ali pega aquele ônibus todo dia.. eu tô ... canso de vê aí tem motorista que fica assim oh (levanta a cabeça imitando o motorista) (risos) aí eu fico pensano... meu Deus tá pior do que eu que sou analfabeta meu Deus do céu (risos) tá pior (...). (Jéssica, Entrevista)

As histórias narradas por Jéssica revelam, assim, suas impressões em relação ao próprio mundo. É nessa perspectiva que Shor e Freire (1986) ressaltam que histórias lidam com o concreto que as classes populares conhecem. Os sujeitos reconhecem, portanto, de forma orgânica, a sua existência. Assim, ao indagarmos novamente sobre sua forma de se expressar, Jéssica ressalta:

[17] (risos) E eu falava tão fei quando eu morava no nordeste.. era tudo errado.. nossa era parecendo uma doida..se a senhora visse. foi depois que eu vim pra cá que eu mudei..intendeu? Mudou o cabelo, mudou meu jeito de falar, mudou meu sorriso, mudei tudo depois que eu cheguei aqui, intendeu? Nossa senhora.. parece uma maluca lá na.. 
porque o pessoal lá você sabe como que é né? na roça o povo não liga nada, intendeu? É tudo jogado.. nossa. mudei..mudou a pele, sabe? Eu fiquei mais branca.. tive mais zelo nos pés que era tudo aquelas.. aqueles cascão de sujeira.. aí tudo. Aí eu aprendi a ficar mais limpa depois que eu cheguei aqui, entendeu? Porque lá era tudo jogado.. o pessoal não via nada (...) Mesmo teve ééé teve um tempo que eu trabalhava na casa de uma mulher aí a mulher falava assim.. oh tu tá falano errado (voz baixa) porque você não sabe falá. é a única palavra que eu não sei falar é auga (água) tem vez que eu falo errado, intendeu? Até hoje eu não aprendi. ai ela olhou assim e disse Jéssica esse negócio ai que tu.. essa palavra aí que tu tá falano tá errado a gente fala auga não é AAuga não (tom de grito) aí até hoje eu não sei falá direito, intendeu? É a única.. mas o resto.. eu falo assim direitinho, intendeu? (...) (Jéssica, Entrevista)

Como já destacamos aqui, a linguagem não se restringe à estrutura linguística de palavras e sentenças, mas é considerada também uma prática social na qual identidades e anseios são contextualmente negociados nas complexas interações sociais, em sua maioria, desiguais (NORTON, 2013). A autora acrescenta, ainda, que a linguagem é constitutiva e constituída pela identidade de um falante e considera que a linguagem é mais do que palavras e sentenças. Bakhtin (2006), por exemplo, considera um grande equívoco afirmar que língua é essencialmente objetiva na sua normatividade estabilizada e incontroversa, mas a língua se faz na (re)significação que as estruturas linguísticas assumem ao serem contextualizadas.

O trecho na entrevista em que Jéssica afirma que, após ter se mudado para Brasília, mudou seu cabelo, o sorriso, a pele (que ficou mais branca, segundo ela) e a sua forma de falar, retrata uma legitimação do preconceito em relação à região nordeste. Observa-se, aqui, a reprodução de um discurso ideológico marcado por padrões dominantes que, assim como a norma culta, regula o que é bonito, o que é feio, o que é bom, o que é ruim. Destaca-se a supremacia de uma cultura sobre a outra, em que a regionalidade vai se descaracterizando em função de um modo supostamente correto de viver, uma forma supostamente correta de falar. Esse momento da entrevista é reconhecido também nas narrativas visuais. Jéssica apresentou duas narrativas. A primeira narrativa visual (Figura 1) representa, segundo ela, o lugar em que nasceu e viveu a sua infância. A segunda narrativa visual (Figura 2) representa, segundo a participante, a forma como ela se vê no momento atual.

Figura 1: Narrativa visual 1 


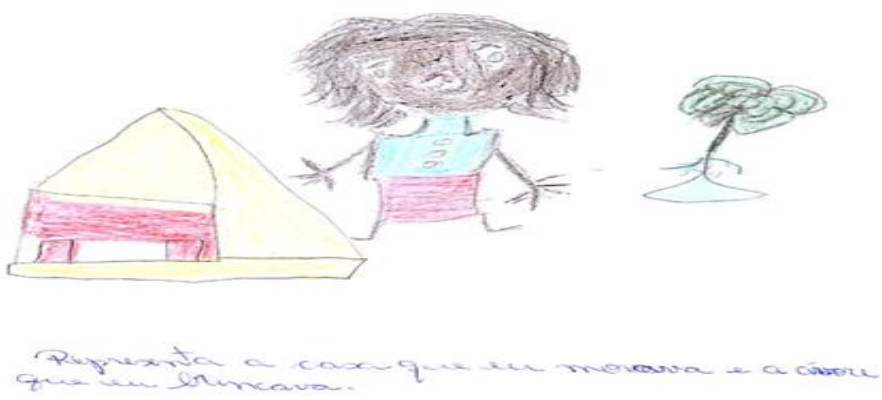

Fonte: Dos dados das autoras.

Figura 2: Narrativa visual 2

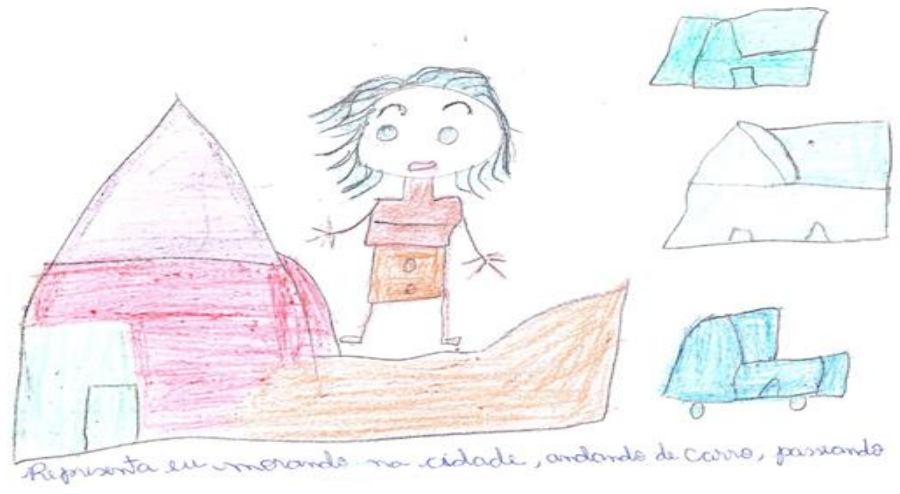

Fonte: Dos dados das autoras.

As narrativas visuais, assim como a explicação oral dos desenhos, fazem transparecer, no discurso de Jéssica, as marcas ideológicas, legitimadas, de que o povo da roça é inferior ao povo da cidade "grande". A quantidade de elementos registrados por Jéssica em seu lugar de origem na Narrativa Visual 1, em relação à quantidade de elementos no seu lugar de moradia atual (Narrativa Visual 2), revela a discrepância entre os cenários afirmada na fala da participante, que toma o lugar de moradia atual como superior. O mesmo se observa na narrativa em relação ao cabelo, que, segundo a participante, ficou mais arrumado e, ainda, o tom da pele, mais branco depois que se mudou para a cidade. Freire (2002) destaca como essas relações dialógicas tornam evidentes as ideologias e as relações de poder, assim como as posições dos sujeitos imersos nos diálogos. As nossas opiniões, relações, modos de linguagem e aprendizagens não são imparciais e neutras, mas sim moldados nas relações sociais que beneficiam algumas pessoas em detrimento de outras, reproduzindo relações desiguais na sociedade. Nesse sentido, o salto para a consciência crítica é perceber a diversidade do discurso e sua natureza posicionada. É preciso lembrar que as sociedades contemporâneas estão se diversificando em vários aspectos, não apenas em relação à etnia e cultura, devido às migrações, mas por adversidades reprimidas por muito tempo (FAIRCLOUGH, 1999).

Mesmo no momento em que as pesquisadoras, durante a entrevista, instigam Jéssica a refletir em relação ao fato de que não existe a linguagem certa ou errada, mas uma variação linguística, em 
tom de espanto, a participante do estudo não admite o jeito de falar de onde ela veio como uma forma correta de falar. Em sua opinião, é preciso afirmar que aquela forma de falar é errada para que se possa melhorar. Segundo ela, sempre que retorna à sua cidade, ela corrige seus irmãos, principalmente, como ela destaca, porque alguns logo irão para a cidade para trabalhar e então têm que aprender o jeito certo de falar:

[18] "Certo (voz de espanto) daquele jeito lá?...certo? (...) é porque eles convive lá naquela roça lá, né? Naquele mato lá... que lá é roça aí eles... todo jeito pra eles conversá tá bom.do jeito que eles trata as pessoas pra eles tá bom......) ah.. Eu acho é o seguinte que se tá errado tem que falá que tá errado pra melhorar. Eu quando eu chego lá eu fico falano pra eles nossa cês tá falano tudo errado gente... não é assim que se fala... a minha irmã morre de ri... oh já chegou ela só porque tá lá em Brasília aí vem diferente aí vem butano moral nos outo.. desse jeito ela fala.. eu digo mas oh eu tô explicano pra vocês po bem de vocês pa quando vocês for na cidade grande que vocês vão crescê e vocês vão pa cidade grande pra vocês já i sabeno conversá direito falá direito (...) E: e você não sente vontade de falar igual eles? não.. ave maria (...): não quero não porque.. eu acho tão estranho fei a pessoa ficá conversano daquele jeito.. ficá xingano, intendeu? Cada palavrão fei.. fica brigano mais o pessoal.. (...) Não eu não tenho essa vontade não ave maria moço.. o que é fei a gente tem que largá é pra lá.. é fei, intendeu?" (Jéssica, Entrevista)

Jéssica não percebe que o que está sendo negado é a sua identidade de origem, seus costumes, sua regionalidade. Na verdade, reconhecer a fala apregoada pela ideologia dominante da norma culta como a única forma de falar é desfazer-se da sua cultura e aderir a uma cultura que serve a interesses majoritários. Assim, neste trabalho, nosso objetivo é justamente a reflexão sobre o hibridismo semiótico que favorece a construção de novas aproximações de linguagem, dialetos sociais, vozes, gêneros e discursos (FAIRCLOUGH, 1999) de forma a fortalecer identidades inferiorizadas, como uma maneira de contribuir para um mundo social menos desigual em que todos tenham voz, a despeito da classe social em que se encontrem situados.

\section{CONSIDERAÇÕES FINAIS}

A partir do anseio de analisar a resistência em relação a aprender a ler e escrever da trabalhadora doméstica Jéssica, buscamos posicionar-nos nesse processo, em um primeiro momento, como questionadoras do problema. Entretanto, por meio deste estudo, (re)significamos nossa postura e, com isso, nossa compreensão dos processos identitários. O olhar para o "não ler e escrever" de Jéssica como um problema que tinha que ser solucionado em uma relação horizontal, deu lugar, assim, à consciência da importância da leitura de mundo de Jéssica.

Jéssica é analfabeta no sentido de não saber ler e escrever, mas a partir dos relatos das suas vivências diárias, percebemos a sua dinamicidade em buscar recursos e estratégias ao exercer o seu papel na sociedade. Entretanto o que mais nos chama atenção na pesquisa é que as angústias da 
entrevistada em relação ao analfabetismo, não estão associadas ao fato de não saber ler e escrever, mas ao analfabetismo explorado por Soares (2010), que destaca a privação dos direitos de cidadã e os discursos de marginalização. Estes provocam em Jéssica a resistência à oportunidade de aprender a ler e escrever, por meio da reprodução dos discursos ideológicos de que deve assumir uma identidade de analfabeta porque tem dificuldade de aprender. Por outro lado, Jéssica parece transformar e (re)significar essa prática discursiva, o seu analfabetismo, ao exercer o seu papel social, todos os dias. Como destaca Fairclough (2016) o discurso como uma prática social está tanto propício ao ajustamento ideológico e linguístico de acomodação, quanto na ação transformadora das suas próprias práticas discursivas, (re)significando a manipulação e os posicionamentos ideológicos socialmente produzidos nos discursos.

A realização deste estudo, possibilitou, assim, uma reflexão mais aprofundada sobre o processo de desnaturalização da condição de não escolarizada de Jéssica, pois esta não se resume à sua resistência por não querer mais aprender a ler e escrever, mas está implicada em suas condições sociais, atreladas às legitimações de crenças, gênero, espaço, tempo e, enfim, a processos sóciohistóricos e culturais. Uma prática social alicerçada em ideologias formalistas instrumentaliza o sujeito para atuar dentro de um contexto puramente serviente e individualista, como parece ser o caso de Jéssica. Logo, as diferenças precisam ser negociadas. É preciso compreender que o empoderamento do outro é o olhar para a história de vida dele. Um indivíduo não é uma tábula rasa porque não foi alfabetizado/a). A linguagem não se restringe à estrutura linguística das palavras, mas é considerada também uma prática social, nas quais identidades e anseios são contextualmente negociados nas complexas interações sociais (NORTON, 2013; 2016).

Assim, concluímos esta reflexão destacando a importância de se construir, questionar e reconstruir, constantemente, não apenas o nosso conceito de identidades, mas também a forma como as identidades estão imersas nas práticas sociais de linguagem. O que é dado ao/à agente social não pode sobrepor-se a um dos fatores mais importantes de sua existência, que é o seu estar no mundo como sujeito histórico e cultural (FREIRE, 2002). E como negociar isso? Certamente, as reflexões sobre os processos identitários trarão possibilidades de (re)construção das identidades, a partir da compreensão de que questões de linguagens e identidades não devem ser compreendidas de forma isolada das condições materiais e das relações de poder em que se encontram circunscritas. 


\section{REFERÊNCIAS}

BAGNO, M.; STUBBS, M.; GAGNÉ, G. Língua Materna: Letramento, variação e ensino. São Paulo: Parábola Editorial, 2002.

BAKHTIN, M. Marxismo e filosofia da linguagem: problemas fundamentais do método sociológico da linguagem. 13. ed. São Paulo: Hucitec, 2006.

BOGDAN, R.; BIKLEN, S. Investigação Qualitativa em Educação: introdução à teoria e aos métodos. Portugal: Porto Editora, 1994.

BRANDÃO, H. N. Introdução à Análise do Discurso. Campinas: Editora da UNICAMP, 2004.

CHOULIARAKI, L; FAIRCLOUGH, N. Discourse in late modernity: rethinking critical discourse analysis. Edinburgh: Edinburgh University Press,1999.

DIAS, J. Analistas de discurso e sua prática teórico e metodológica. Cadernos de Linguagem e Sociedade, v. 12, p. 213-246, 2011.

FAIRCLOUGH, N. Discurso e mudança social. Coord. trad. rev. técnica e prof. Izabel Magalhães. Brasília: Editora: Universidade de Brasília, 2016.

FAIRCLOUGH, N. Global Capitalism and critical analysis of language. Language Awareness, v. 8, n. 2, p. 71-83, 1999.

FLICK, U. Introdução à pesquisa qualitativa. 3. ed. Porto Alegre: Artmed, 2010.

FREIRE, P. Educação e mudança. Rio de Janeiro: Paz e Terra, 1979.

FREIRE, P. Ação cultural para a liberdade e outros escritos. Rio de Janeiro: Paz e Terra, 1981.

FREIRE, P. A importância do ato de ler: em três artigos que se completam. 23. ed. São Paulo: Cortez, 1989.

FREIRE, P. Pedagogia da Autonomia: saberes necessários à prática educativa. São Paulo: Paz e Terra, 2002.

FREIRE, P. Pedagogia do Oprimido. 43. ed. Rio de Janeiro: Paz e Terra, 2005.

HALL, S. A identidade cultural na pós-modernidade. Tradução Tomaz Tadeu da Silva, Guaracira Lopes. 7. ed., Rio de Janeiro: DP\&A, 2006.

HAWKINS, M.; NORTON, B. Critical language teacher education. In: BURNS, A.; RICHARDS, J. (ed.). Cambridge guide to second language teacher education. Cambridge, Cambridge University Press, 2009. p. 30-39.

MAGALHÃES, I. Introdução: a análise de discurso crítica. DELTA, v. 21, p. 1-9, 2005.

MELO-PFEIFER, S. Multilingual awareness and heritage language education: children's multimodal representations of their multilingualism, 2015. Disponível em:

https://doi.org/10.1080/09658416.2015.1072208. Acesso em: 02 maio 2018. 
MOSCOVICI. S. Representações Sociais: investigações em psicologia social. Rio de Janeiro:

Vozes, 2013.

NORTON, B. Identity and language learning: Gender, ethnicity and educational change. Harlow, England: Pearson Education Limited, 2000.

NORTON, B. Identity and language learning: Extending the conversation. 2. ed., Bristol: Multilingual Matters, 2013.

NORTON, B. Identity and language learning: Back to the future. TESOL Quarterly, v. 50, n. 2, p. 475-479, 2016.

RESENDE, V. de M; RAMALHO, V. C. V. S. Análise de Discurso Crítica, do modelo tridimensional à articulação entre práticas: implicações teórico-metodológicas. Linguagem em (Dis)curso, v. 5, n. 1, p. 185-208, 2010.

RESENDE, V. de M.; RAMALHO, V. C. V. S. Análise de Discurso (para a) Crítica: o texto como material de pesquisa. São Paulo: Pontes Editores, 2011.

SHOR, I.; FREIRE, P. Medo e Ousadia: O Cotidiano do Professor. Rio de Janeiro: Paz e Terra, 1986.

SOARES, M. Letramento: um tema em três gêneros. Belo Horizonte: Autêntica Editora, 2010. 